\title{
Maternal Predictors of Newborn Somatometrics
}

\author{
Satwanti Kapoor, Prerna Bhasin, Meenal Dhall, Deepali Verma, Shilpi Gupta, \\ and Mary Grace Tungdim
}

Department of Anthropology, University of Delhi, Delhi 110007, India

Correspondence should be addressed to Satwanti Kapoor, satwanti@yahoo.com

Received 18 November 2011; Revised 23 January 2012; Accepted 23 January 2012

Academic Editor: Kaushik Bose

Copyright ( $) 2012$ Satwanti Kapoor et al. This is an open access article distributed under the Creative Commons Attribution License, which permits unrestricted use, distribution, and reproduction in any medium, provided the original work is properly cited.

The objective of the study was to ascertain the influence of various maternal factors like age, BMI, anthropometry, parity, and so forth on body dimensions of newborn and to discover determinants of neonatal subcutaneous fat distribution pattern. 94 Khatri and Arora new borns along with their biological mothers hailing from upper/middle socioeconomic status families were selected against several criteria: only liveborn, healthy full term babies (37-41 gestational weeks), singletons, born through vaginal delivery and for whom all data were available, for the study. Numerous biometric variables were chosen for this study: weight, stature (for mothers), birth length (for neonates), circumferences (head, chest, abdomen, hip, upper arm, and wrist), and skinfolds at different sites (biceps, triceps, subscapular, suprailiac, chest, thigh anterior, and calf posterior) along with newborn's birth weight. All LBW infants were found to be significantly associated with maternal nutritional status and age, when controlled for other factors. Chances of having an LBW infant varies with mother's nutritional status as determined by BMI and MUAC. Fat profiling has genetic implications because fat tracking patterns have shown that, irrespective of maternal nutritional status and age, most neonate skinfolds are guided by mother's skinfold thicknesses. We conclude that early teenage pregnancies should be discouraged so as to reduce the incidence of LBW and larger ethnic-specific studies should be taken to find determinants of subcutaneous fat pattern in neonates.

\section{Introduction}

Various genetic and environmental factors are known to influence the size of newborns. Numerous studies have shown the significant effects of various maternal factors on the somatometrics characteristics of the newborns [1-5]. Some of the biometric maternal predictors reflect the genetic blueprint laid down for the newborn, while other predictors are more of an expression of the environmental influences. Hence, most of the newborn characteristics echo a complex combination of both genetic and nutritional (maternal) factors.

Maternal body dimensions are first determinants of neonate biometrics, predominantly their birth weight and length, which are closely related to perinatal morbidity and mortality. While among the nonbiometric maternal factor, two factors known to play a decisive role in fetal growth are maternal age and parity [6]. Mother's nutritional status is also known to be a key indicator of infant's body dimensions and its early growth features. Birth weight and length are clearly based on mother's nutritional [7] and anthropometric factors [8], respectively, showing a striking genetic influence [9]. The essentials of neonate fat profiling and the trends in association with maternal elements are still to be determined.

Therefore, the objective of the study is to ascertain the influence of various maternal factors like age, BMI, anthropometry, parity, and so forth on body dimensions of newborn. Determinants of neonatal subcutaneous fat distribution pattern have also been focused on with special attention to the intricate effects of age, nutritional status, and parity.

\section{Material and Methods}

2.1. Characteristics of the Population. This study is based on a cross-sectional sample of neonates (mean age $8 \pm 0.01$ days) along with their biological mothers (mean age $24.33 \pm 4.03$ years) from maternity ward of a New Delhi hospital. In total, 94 subjects from upper/middle socioeconomic status families 
TABLE 1: Descriptive statistics of newborn characteristics according to BMI categories with $F$ values and LSD post hoc test.

\begin{tabular}{|c|c|c|c|c|}
\hline \multirow[b]{2}{*}{ Variables } & \multicolumn{3}{|c|}{ Mean \pm SD } & \multirow[b]{2}{*}{$F$ value } \\
\hline & $\begin{array}{c}\text { Underweight } \\
(23.4 \%)\end{array}$ & $\begin{array}{c}\text { Normal } \\
(67.02 \%)\end{array}$ & $\begin{array}{c}\text { Overweight } \\
(9.57 \%)\end{array}$ & \\
\hline Length & $48.76 \pm 2.04$ & $49.03 \pm 2.02$ & $52.63 \pm 2.01$ & $6.47^{* *}$ \\
\hline Weight & $2.54 \pm 0.48$ & $2.69 \pm 0.50$ & $3.25 \pm 0.65$ & $3.70^{*}$ \\
\hline Birth weight & $2.67 \pm 0.33$ & $2.75 \pm 0.41$ & $3.22 \pm 0.49$ & $3.35^{*}$ \\
\hline Head circumference & $32.47 \pm 0.99$ & $33.00 \pm 1.39$ & $38.95 \pm 10.70$ & $14.62^{* * *}$ \\
\hline Chest circumference & $29.41 \pm 2.19$ & $30.21 \pm 2.46$ & $32.45 \pm 2.31$ & $3.14^{*}$ \\
\hline Waist circumference & $28.40 \pm 2.19$ & $29.26 \pm 2.16$ & $29.68 \pm 6.01$ & NS \\
\hline Upper arm circumference & $8.45 \pm 0.59$ & $8.54 \pm 0.72$ & $9.70 \pm 1.32$ & $5.43^{* *}$ \\
\hline Wrist circumference & $6.77 \pm 0.49$ & $6.87 \pm 0.51$ & $7.40 \pm 0.59$ & $2.68^{*}$ \\
\hline Thigh circumference & $12.40 \pm 1.30$ & $12.36 \pm 1.44$ & $14.03 \pm 1.55$ & NS \\
\hline Ankle circumference & $7.24 \pm 0.69$ & $7.21 \pm 0.58$ & $8.05 \pm 0.53$ & $3.50^{*}$ \\
\hline Biceps skinfold thickness & $3.78 \pm 0.75$ & $3.73 \pm 0.68$ & $5.10 \pm 1.09$ & $6.88^{* *}$ \\
\hline Triceps skinfold thickness & $4.74 \pm 0.89$ & $4.70 \pm 0.99$ & $6.40 \pm 1.34$ & $5.80^{* *}$ \\
\hline Subscapular skinfold thickness & $4.32 \pm 1.18$ & $4.21 \pm 0.74$ & $5.70 \pm 1.31$ & $5.08^{* *}$ \\
\hline Suprailiac skinfold thickness & $4.11 \pm 1.15$ & $3.78 \pm 0.80$ & $5.50 \pm 1.05$ & $7.12^{* *}$ \\
\hline Chest skinfold thickness & $3.50 \pm 0.83$ & $3.43 \pm 0.66$ & $5.35 \pm 1.32$ & $12.57^{* * *}$ \\
\hline Thigh skinfold thickness & $5.91 \pm 1.26$ & $5.61 \pm 1.23$ & $8.10 \pm 2.52$ & $6.98^{* *}$ \\
\hline Calf posterior skinfold thickness & $5.42 \pm 0.94$ & $5.32 \pm 0.98$ & $6.15 \pm 1.23$ & NS \\
\hline
\end{tabular}

${ }^{* * *} p<0.001,{ }^{* *} p<0.01,{ }^{*} p<0.05$, NS-nonsignificant.

TABLe 2: Descriptive statistics of newborn characteristics and age of mother with $t$ values.

\begin{tabular}{|c|c|c|c|}
\hline \multirow{3}{*}{ Variables } & \multicolumn{2}{|c|}{ Age of Mother (AOM) } & \multirow{3}{*}{$t$ value } \\
\hline & $<20$ years & $\geq 20$ years & \\
\hline & Mean \pm SD & Mean \pm SD & \\
\hline Length & $48.28 \pm 2.18$ & $49.36 \pm 2.10$ & $-1.99^{*}$ \\
\hline Weight & $2.58 \pm 0.42$ & $2.69 \pm 0.40$ & $-0.89^{*}$ \\
\hline Birth weight & $2.63 \pm 0.44$ & $2.77 \pm 0.53$ & $-1.38^{* *}$ \\
\hline Head circumference & $32.89 \pm 1.46$ & $36.96 \pm 5.14$ & NS \\
\hline Chest circumference & $30.65 \pm 3.61$ & $29.91 \pm 1.99$ & NS \\
\hline Waist circumference & $28.96 \pm 1.90$ & $29.07 \pm 2.53$ & NS \\
\hline Upper arm circumference & $8.41 \pm 0.82$ & $8.61 \pm 0.73$ & NS \\
\hline Wrist circumference & $6.78 \pm 0.66$ & $6.89 \pm 0.47$ & NS \\
\hline Thigh circumference & $12.14 \pm 1.93$ & $12.53 \pm 1.26$ & NS \\
\hline Ankle circumference & $7.09 \pm 0.67$ & $7.30 \pm 0.61$ & NS \\
\hline Biceps skinfold thickness & $3.43 \pm 0.73$ & $3.90 \pm 0.74$ & $-2.55^{*}$ \\
\hline Triceps skinfold thickness & $4.33 \pm 0.95$ & $4.91 \pm 1.01$ & $-2.30^{*}$ \\
\hline Subscapular skinfold thickness & $4.05 \pm 0.96$ & $4.36 \pm 0.93$ & $-1.33^{*}$ \\
\hline Suprailiac skinfold thickness & $3.84 \pm 0.98$ & $3.96 \pm 0.99$ & $-0.50^{*}$ \\
\hline Chest skinfold thickness & $3.28 \pm 0.72$ & $3.60 \pm 0.84$ & NS \\
\hline Thigh skinfold thickness & $5.46 \pm 1.42$ & $5.89 \pm 1.36$ & $-1.25^{*}$ \\
\hline Calf posterior skinfold thickness & $5.02 \pm 0.87$ & $5.48 \pm 0.99$ & $-1.87^{*}$ \\
\hline
\end{tabular}

${ }^{* *} p<0.01,{ }^{*} p<0.05$, NS-nonsignificant.

were selected against several criteria: only liveborn, healthy full term babies (37-41 gestational weeks), singletons, born through vaginal delivery and for whom all data were available, were included in the study. To ensure the genetic consistency of the sample, it was restricted to Punjabi Khatris and
Aroras mothers, who were matched for age and SES. These ethnic groups are known to have common ancestry and also cross-marry.

Mothers' ages were grouped into two age intervals: $<20$ years (teenage mothers) with mean age $16.9 \pm 2.12$ years and 
TABle 3: Percentage distribution of babies with respect to their birth weight on the basis of age of mother, mother's MUAC and maternal BMI.

\begin{tabular}{lcccc}
\hline \multicolumn{5}{c}{ Birth weight } \\
\multicolumn{2}{c}{ Variables and standards } & $\begin{array}{c}<2.5 \mathrm{~kg} \\
(\mathrm{LBW})\end{array}$ & $>2.5 \mathrm{kgs}$ & Chi-square \\
\hline Age of & $<20$ years & $55 \%$ & $45 \%$ & $3.431^{*}$ \\
mother & $\geq 20$ years & $32.4 \%$ & $67.6 \%$ & \\
\multirow{2}{*}{ MUAC } & $<22 \mathrm{~cm}$ & $53.2 \%$ & $46.8 \%$ & $3.687^{*}$ \\
& $\geq 22 \mathrm{~cm}$ & $27.7 \%$ & $72.3 \%$ & \\
BMI & Underweight & $59.3 \%$ & $40.7 \%$ & \\
categories & Normal & $48.3 \%$ & $61.7 \%$ & $5.88^{*}$ \\
& Overweight/obese & 0 & $100 \%$ & \\
${ }_{*}^{*} p<0.05$. & & & & \\
& & & &
\end{tabular}

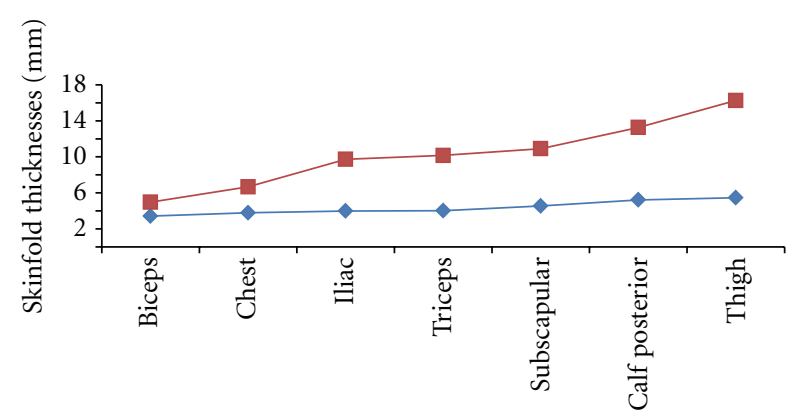

Skinfold sites

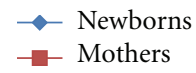

Figure 1: Fat distribution pattern at different sites for mothers and babies when $\mathrm{AOM}<20$ years.

$\geq 20$ years (adult mothers) with mean age $25.3 \pm 3.63$ years. Parity was categorized from 1 (primiparous women) to 4 (multiparous women). Neonates were categorized on basis of birth weight into two groups, LBW $<2.5 \mathrm{~kg}$ and normal weight $\geq 2.5 \mathrm{~kg}$ [10]. Research proformas were used for recording details of previous medical histories, socio-economic status and demographic data.

Informed written consent was obtained from each subject. All the subjects were apparently healthy with no visible deformity.

2.2. Sample Size and Power Calculation. The power for the sample was calculated using statistical power calculator [11], and acquiring means for birth weight, length, and head circumferences. For reference values, data from a previous study [12] was acquired. At confidence interval 5\%, the maximum power calculated was $62.6 \%$.

2.3. Biometric Data. From the numerous biometric variables available in the data set, following variables that were representative of the overall dimensions of the sample population were chosen for this study: weight, stature (for mothers), birth length (for neonates), circumferences in $\mathrm{cms}$, to within

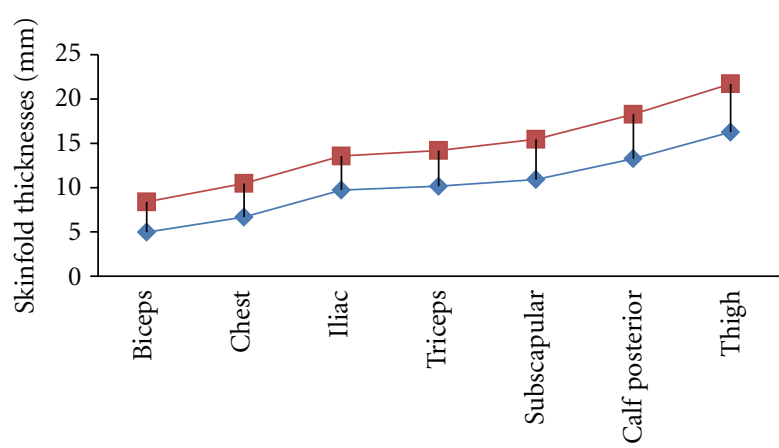

Skinfold sites

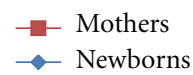

Figure 2: Tracking fat distribution pattern at different sites for mothers and babies when $\mathrm{AOM}<20$ years.

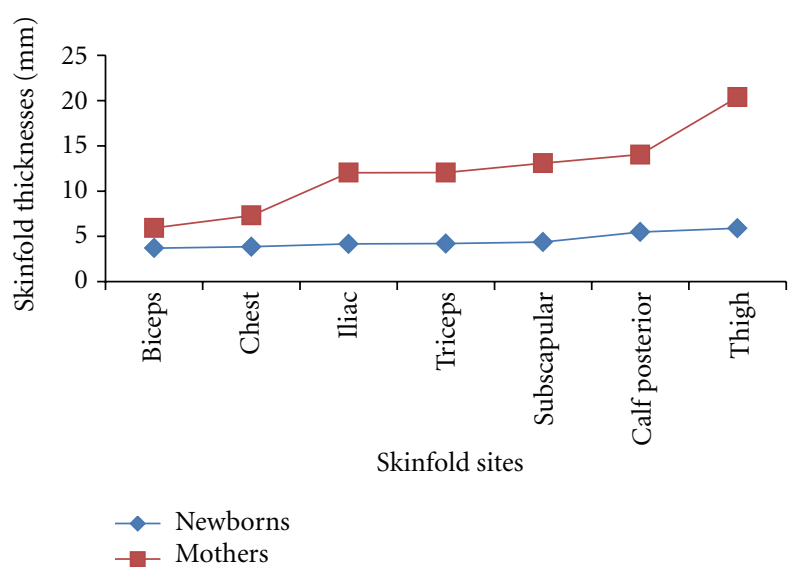

FIGURE 3: Fat distribution pattern at different sites for mothers and babies when $\mathrm{AOM}>20$ years.

$1 \mathrm{~mm}$ (head, chest, abdomen, hip, upper arm, and wrist), and skinfolds at different sites (biceps, triceps, subscapular, suprailiac, chest, thigh anterior, and calf posterior) measured by means of Harpenden skinfold caliper with $0.2 \mathrm{~mm}$ precision. All measurements were taken by using standard technique of Weiner and Lourie, 1981 [13]. Birth weight of the newborns was acquired through secondary sources and that of mothers was measured with the help of a spring balance to the nearest $0.5 \mathrm{~kg}$.

2.4. Analysis. Analysis of variance (ANOVA) and $t$-test were used to test the differences in newborn biometry in relation to BMI of the mother and age, respectively. ANOVA tests the effect of the independent nominal variables on the continuous dependent variables (newborn dimensions). LSD post hoc was used to find subtle differences between newborns' parameter on the basis of maternal BMI.

Regression models tests, for various maternal variables (age, parity, BMI, MUAC) with BW as dependent variable, were performed. This method helps in the choice of the 
TABLE 4: Regression coefficients of birth weight and its significance in the multivariable model of logistic regression for MUAC (mid-upper arm circumference) of the mother, AOM (age of mother) and maternal body mass index (BMI).

\begin{tabular}{llccc}
\hline \multicolumn{2}{c}{ Birth weight } & B & Std. error of B & Exp B (95\% CI) \\
\hline \multirow{2}{*}{ MUAC } & $<22 \mathrm{~cm}$ (undernourished) & 0.939 & 0.277 & $2.559(1.927-4.063)$ \\
& $\geq 22 \mathrm{~cm}$ (normal) & - & & 0.00 (referent) \\
\multirow{2}{*}{ AOM } & $<20$ years (teenage) & 0.669 & 0.201 & $1.951(1.677-3.621)$ \\
& $\geq 20$ years & - & & 0.00 (referent) \\
\multirow{2}{*}{ BMI } & Normal $(\geq 18.5)$ & -0.204 & 0.129 & $0.816(0.472-0.908)$ \\
& Underweight $(\leq 18.49)$ & - & & 0.00 (referent) \\
\hline
\end{tabular}

TABle 5

\begin{tabular}{|c|c|c|c|c|c|c|c|}
\hline \multirow{2}{*}{ Infant's variable } & \multirow{2}{*}{$\begin{array}{l}\text { (I) BMI of the } \\
\text { mother }\end{array}$} & \multirow{2}{*}{$\begin{array}{l}\text { (J) BMI of the } \\
\text { mother }\end{array}$} & \multirow{2}{*}{$\begin{array}{l}\text { Mean } \\
\text { difference } \\
(\mathrm{I}-\mathrm{J})\end{array}$} & \multirow{2}{*}{ Std. error } & \multicolumn{3}{|c|}{$95 \%$ confidence interval } \\
\hline & & & & & Sig. & $\begin{array}{l}\text { Lower } \\
\text { bound }\end{array}$ & $\begin{array}{l}\text { Upper } \\
\text { bound }\end{array}$ \\
\hline \multirow{2}{*}{ Length } & \multirow{2}{*}{ Overweight } & Underweight & $3.75^{*}$ & 1.09 & 0.00 & 1.58 & 5.92 \\
\hline & & Normal weight & $3.59^{*}$ & 1.05 & 0.00 & 1.51 & 5.69 \\
\hline \multirow{2}{*}{ Weight } & \multirow{2}{*}{ Overweight } & Underweight & $0.54^{*}$ & 0.21 & 0.01 & 0.13 & .97 \\
\hline & & Normal weight & $0.48^{*}$ & 0.20 & 0.02 & 0.07 & .87 \\
\hline \multirow{2}{*}{ Birth weight } & \multirow{2}{*}{ Overweight } & Underweight & $0.71^{*}$ & 0.26 & 0.01 & 0.19 & 1.24 \\
\hline & & Normal weight & $0.56^{*}$ & 0.26 & 0.03 & 0.06 & 1.07 \\
\hline \multirow{2}{*}{ Head circumference } & \multirow{2}{*}{ Overweight } & Underweight & $76.41^{*}$ & 14.64 & 0.00 & 47.33 & 105.49 \\
\hline & & Normal weight & $75.95^{*}$ & 14.13 & 0.00 & 47.88 & 104.02 \\
\hline \multirow{2}{*}{ Chest circumference } & \multirow{2}{*}{ Overweight } & Underweight & $3.03 *$ & 1.26 & 0.02 & 0.52 & 5.54 \\
\hline & & Normal weight & 2.24 & 1.22 & 0.07 & -0.19 & 4.66 \\
\hline \multirow{2}{*}{ Waist circumference } & \multirow{2}{*}{ Overweight } & Underweight & 1.18 & 1.28 & 0.36 & -1.37 & 3.73 \\
\hline & & Normal weight & .42 & 1.24 & 0.74 & -2.04 & 2.87 \\
\hline \multirow{2}{*}{ Waist circumference } & \multirow{2}{*}{ Overweight } & Underweight & $1.23^{*}$ & 0.38 & 0.00 & 0.47 & 1.99 \\
\hline & & Normal weight & $1.16^{*}$ & 0.37 & 0.00 & 0.43 & 1.89 \\
\hline \multirow{2}{*}{ Upper arm circumference } & \multirow{2}{*}{ Overweight } & Underweight & $1.23^{*}$ & 0.38 & 0.00 & 0.47 & 1.99 \\
\hline & & Normal weight & $1.16^{*}$ & 0.37 & 0.00 & 0.43 & 1.89 \\
\hline \multirow{2}{*}{ Wrist circumference } & \multirow{2}{*}{ Overweight } & Underweight & $0.61^{*}$ & 0.27 & 0.03 & 0.07 & 1.15 \\
\hline & & Normal weight & $0.52^{*}$ & 0.26 & 0.05 & 0.01 & 1.05 \\
\hline \multirow{2}{*}{ Thigh circumference } & \multirow{2}{*}{ Overweight } & Underweight & $1.61^{*}$ & 0.75 & 0.03 & 0.12 & 3.10 \\
\hline & & Normal weight & $1.61^{*}$ & 0.72 & 0.02 & 0.23 & 3.10 \\
\hline Ankle circumference & Overweight & Underweight & $0.81^{*}$ & 0.33 & 0.01 & 0.16 & 1.46 \\
\hline & & Normal weight & $0.83^{*}$ & 0.32 & 0.01 & 0.21 & 1.46 \\
\hline Biceps skinfold thickness & Overweight & Underweight & $1.32^{*}$ & 0.38 & 0.00 & 0.56 & 2.08 \\
\hline & & Normal weight & $1.37^{*}$ & 0.37 & 0.00 & 0.64 & 2.10 \\
\hline Triceps skinfold thickness & Overweight & Underweight & $1.65^{*}$ & 0.52 & 0.00 & 0.63 & 2.68 \\
\hline & & Normal weight & $1.73^{*}$ & 0.50 & 0.00 & 0.71 & 2.69 \\
\hline Subscapular skinfold & Overweight & Underweight & $1.40^{*}$ & 0.48 & 0.00 & 0.44 & 2.36 \\
\hline thickness & 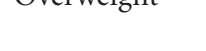 & Normal weight & $1.49^{*}$ & 0.47 & 0.00 & 0.57 & 2.42 \\
\hline Suprailiac skinfold & Oyerweight & Underweight & $1.43^{*}$ & 0.49 & 0.00 & 0.45 & 2.41 \\
\hline thickness & & Normal weight & $1.72^{*}$ & 0.48 & 0.00 & 0.77 & 2.67 \\
\hline Chest skinfold thickness & Overweight & Underweight & $1.86^{*}$ & 0.39 & 0.00 & 1.07 & 2.64 \\
\hline & & Normal weight & $1.92^{*}$ & 0.38 & 0.00 & 1.16 & 2.67 \\
\hline Thioh skinfold thickness & Oyerweight & Underweight & $2.21^{*}$ & 0.69 & 0.00 & 0.83 & 3.59 \\
\hline Н Н1 & 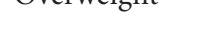 & Normal weight & $2.49^{*}$ & 0.67 & 0.00 & 1.16 & 3.82 \\
\hline Calf posterior skinfold & Overweight & Underweight & 0.74 & 0.52 & 0.16 & -0.29 & 1.78 \\
\hline thickness & eververgiti & Normal weight & 0.83 & 0.50 & 0.10 & -0.16 & 1.83 \\
\hline
\end{tabular}




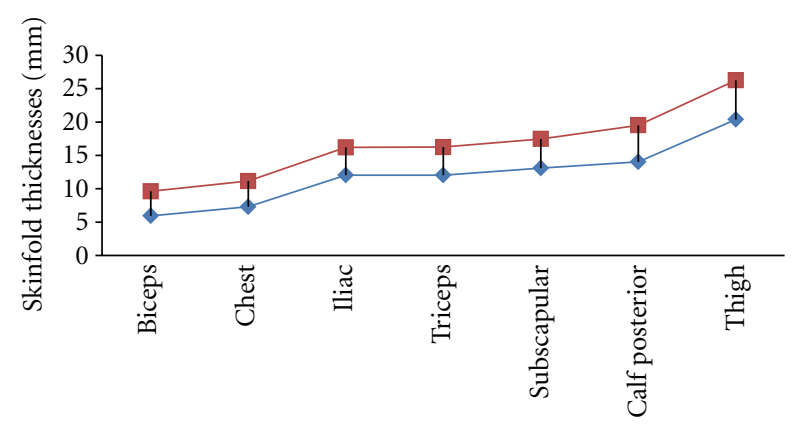

Skinfold sites

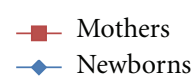

FIgURE 4: Tracking fat distribution pattern at different sites for mothers and babies when $\mathrm{AOM} \geq 20$ years.

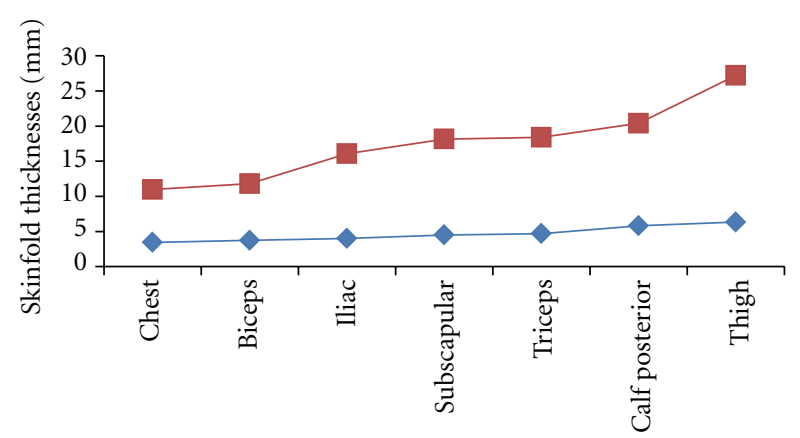

Skinfold sites

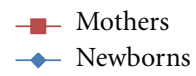

FIGURE 5: Fat distribution pattern at different sites for mothers and babies when mothers are overweight/obese (BMI).

independent variables that are most useful in explaining or predicting the dependent biometric parameter in the newborn variable. The test revealed effects of maternal nutritional status through maternal BMI [14] and MUAC [15] on infant's nutritional status through birthweight (BW). Chi-square test has also been used to further substantiate the effect of maternal parameters on newborn biometrics.

SPSS 17 has been used for data analysis and full results of these tests are available on request.

\section{Results}

For inferential parametric analysis, $F$-test and $t$-test were used as shown in Tables 1 and 2, respectively. There were significant differences in neonatal characteristics such as length, weight, birth weight, circumferences (head, chest, upperarm, wrist, thigh, ankle), and skinfold thickness at various sites (biceps, triceps, skinfold, subscapular, suprailiac, chest, thigh) among the three groups of infants when classified according to their biological mothers postpregnancy BMI

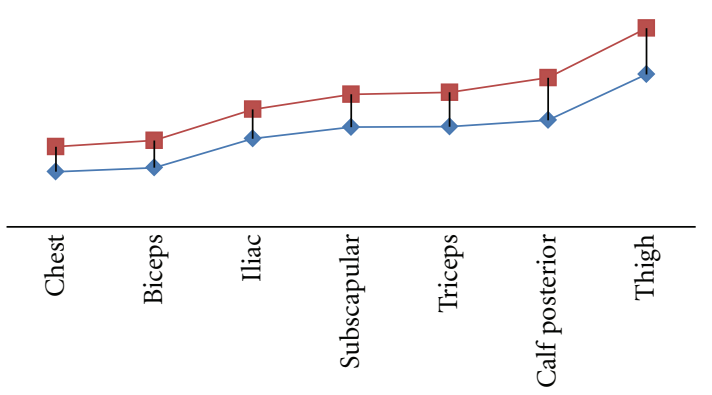

Skinfold sites

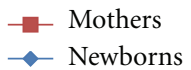

FIgURE 6: Tracking fat distribution pattern at different sites for mothers and babies when mothers are normal (BMI).

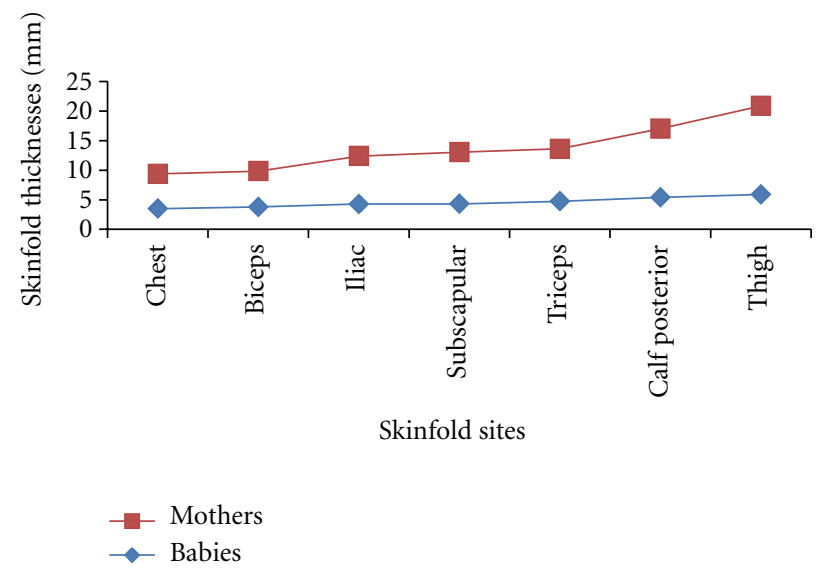

Figure 7: Fat distribution pattern at different sites for mothers and babies when mothers are underweight (BMI).

(Table 1). All characteristic values of infants of obese mothers were greater as compared with both their normal and lean counterparts. Similarly, except for circumferences and chest skinfold thickness, significant differences were found among two groups of infants classified according to their biological mothers age (Table 2). The post hoc tests have been enumeated in Table 5. Infants of teenage mothers had lower characteristic values than their adult equivalents (age $\geq 20$ years).

Table 3 shows the influence of maternal characteristics on neonate's nutritional status with respect to the birth weight. Teenage mothers and mothers with poor nutritional status $\left(\right.$ BMI $<18.5 \mathrm{~kg} / \mathrm{m}^{2}$ and MUAC $<22 \mathrm{~cm}$ ) were seen to be significant determinants of infant's birth weight $(p<0.05)$.

Mother's age, BMI, parity, and MUAC were entered into a multivariate logistic regression model, along with an indicator for infant's nutritional status (BW) as shown in Table 4. After adjusting for other maternal characteristics, the odds of giving birth to an LBW infant were more than 2.5 (odds ratio $[\mathrm{OR}]=2.559 ; 95 \% \mathrm{CI}, 1.927-4.063 ; p<0.05)$ times for an undernourished mother (MUAC $<22 \mathrm{~cm}$ ) and the results 


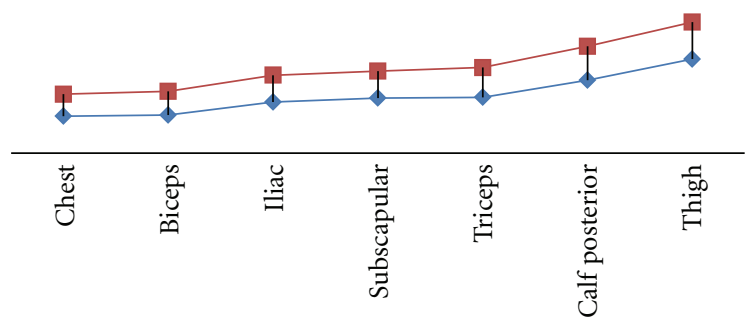

Skinfold sites

- Mothers

$\multimap$ Newborns

Figure 8: Tracking fat distribution pattern at different sites for mothers and babies when mothers are underweight (BMI).

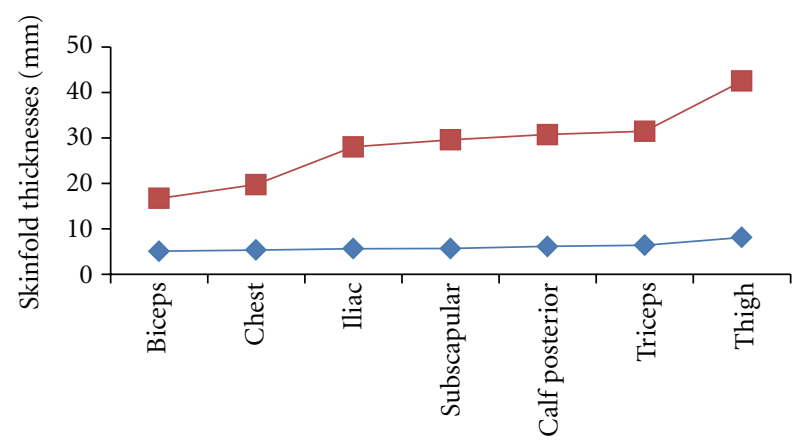

Skinfold sites

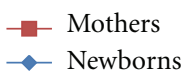

FIGURE 9: Fat distribution pattern at different sites for mothers and babies when mothers are overweight/obese (BMI).

showed $19 \%$ (odds ratio $[\mathrm{OR}]=0.816 ; 95 \%$ CI, $0.472-0.908$; $p<0.05)$ lesser chances of giving birth to an underweight infant with increasing maternal BMI for teenage mothers; chances of an LBW infant were 2.0 times higher, (odds ratio $[\mathrm{OR}]=1.95 ; 95 \%$ CI, 1.677-3.621; $p<0.05)$. Results for parity did not reach statistical significance at the $5 \%$ level.

Fat distribution pattern at different sites for teenage mothers and adult mothers along with their infants has been shown in Figures 1 and 3, and their profiles have been tracked in Figures 2 and 4. Similarly, Figures 5, 7, and 9, reveal fat distribution pattern at different sites according to maternal BMI (underweight, normal, and overweight/obese, resp.) for mothers and infants with fat profiles being tracked in subsequent figures (Figures 6, 8, and 10). Regardless of maternal nutritional status and age, the infant fat profile runs almost parallel to the maternal fat distribution pattern indicating a remarkable genetic influence except for skinfold thickness at calf (posterior) and thigh.

\section{Discussion}

Periods of fetal and infant growth are vital predictors of child's health status which are largely determined by

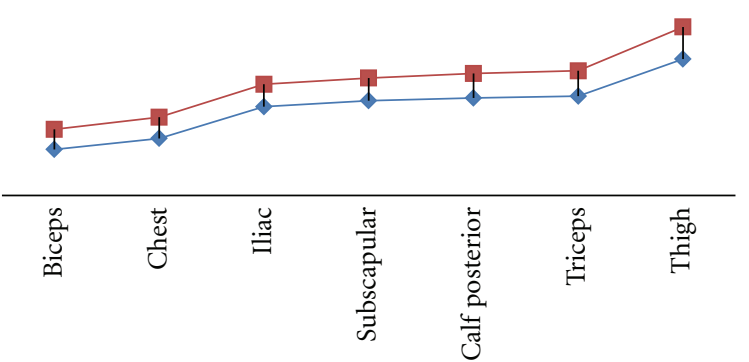

Skinfold sites

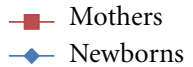

FIgURE 10: Tracking fat distribution pattern at different sites for mothers and babies when mothers are overweight/obese (BMI).

maternal characteristics. Hence, maternal anthropometry and indicators of maternal nutritional status are crucial prognosticators of pregnancy outcomes as they reflect genetic aspects, skeletal maturity and give an account of nutritional conditions.

In the present study, all LBW infants are significantly associated with maternal nutritional status and age, when controlled for other factors as they are not preterm babies. There are strong epidemiological evidences of a relation between maternal nutritional status and birth weight resulting in a number of intervention studies of nutritional supplementation during pregnancy that have been carried out both in developing and developed countries [16]. Birth outcomes, therefore, such as neonatal body size are seen to be a mere manifestation of maternal dynamic complex encompassing biologic, socioeconomic, and demographic factors.

Neggers et al. reported maternal prepregnancy weight to be the best predictor of all neonatal size measures except for the neonatal skinfold thicknesses, which were better predicted by the pre-pregnancy BMI [17]. Newborns' of teenage and undernourished mothers are seen to be leaner than their other counterparts born to adult and healthier mothers. Maternal age in general is an important predictor for successful female fertility outcome. The results of the study testify obstetrical, social, and biopsychosocial aspects associated with teenage pregnancies [18]. An LBW baby might be an aftermath of the biological immaturity of a teenage mother. With review of the literature, it has been evident that most of the studies related to nutritional status use BMI and upper arm circumferences along with its derivatives. The present study shows how chances of having an LBW infant vary with mother's nutritional status as determined by BMI and MUAC.

Adaptation of the mother's vascular system to the transfer of energy to the foetus is an important determinant for newborn subcutaneous fat storage [6], but this adaptation cannot simply be an extension of parity. Skinfold thickness does not only depend on the nutritional status of the mother and age. This fat profiling definitely has genetic implications because fat tracking patterns have shown that, irrespective of 
maternal nutritional status and age, most neonate skinfolds are guided by mother's skinfold thicknesses. The parallelism between maternal and infant fat profile lines justifies this guidance. In this study, the effect of parity was essentially limited and did not show significant effects. This study is the first to mention the singularity of skinfold thickness as predicted, not only by the nutritional status of the mother and its genetic connotations.

Maternal nutrition is one of the most modifiable characteristics among the major environmental causes of IUGR in the developing world, and if taken care of, a substantial fraction of LBW could possibly be prevented. In turn this might reduce the prevalence of mortality, morbidity, physical and mental development and factors associated with LBW. However, role of other environmental factors may indeed directly affect these outcomes independent of birth weight [19]. Absence of data on pre-pregnancy weight, actual gestational age, certain factors during the course of pregnancy and a small sample size are limitations of the present study.

\section{Conclusions}

We conclude that early teenage pregnancies should be discouraged so as to reduce the incidence of LBW. There should be apposite health awareness and health promotion policies formulated to spread a word about nutritional wellbeing of the mother for her progeny. Finally, studies similar to the present one should be undertaken at larger scale and among various other ethnic groups of India to understand the determinants of subcutaneous fat pattern in neonates.

\section{Acknowledgments}

The authors are grateful to all the subjects who volunteered for the study and to the Physiological Anthropology Laboratory, Department of Anthropology, University of Delhi, Delhi, India, for providing the infrastructure. S. Kapoor is grateful to CSIR for providing financial assistance.

\section{References}

[1] S. Kirchengast, B. Hartmann, K. W. Schweppe, and P. Husslein, "Impact of maternal body build characteristics on newborn size in two different European populations," Human Biology, vol. 70, no. 4, pp. 761-774, 1998.

[2] S. MacLeod and J. L. Kiely, "The effects of maternal age and parity on birthweight: a population-based study in New York City," International Journal of Gynecology and Obstetrics, vol. 26, no. 1, pp. 11-19, 1988.

[3] Y. Feleke and F. Enquoselassie, "Maternal age, parity and gestational age on the size of the newborn in Addis Ababa," East African Medical Journal, vol. 76, no. 8, pp. 468-471, 1999.

[4] S. Malik, R. G. Ghidiyal, R. Udani, and P. Waingankar, "Maternal biosocial factors affecting low birth weight," Indian Journal of Pediatrics, vol. 64, no. 3, pp. 373-377, 1997.

[5] K. Dhall and R. Bagga, "Maternal determinants of birth weight of North Indian babies," The Indian Journal of Pediatrics, vol. 62, no. 3, pp. 333-344, 1995.

[6] A. M. Guihard-Costa, E. Papiernik, and S. Kolb, "Maternal predictors of subcutaneous fat in the term newborn," Acta
Paediatrica, International Journal of Paediatrics, vol. 93, no. 3, pp. 346-349, 2004.

[7] S. Muthayya, "Maternal nutrition \& low birth weight-what is really important?" Indian Journal of Medical Research, vol. 130, no. 5, pp. 600-608, 2009.

[8] F. R. Witter and B. Luke, "The effect of maternal height on birth weight and birth length," Early Human Development, vol. 25, no. 3, pp. 181-186, 1991.

[9] S. R. Veena, G. V. Krishnaveni, A. K. Wills, J. C. Hill, and C. H. D. Fall, "A principal components approach to parent-tonewborn body composition associations in South India," BMC Pediatrics, vol. 9, no. 1, article 16, 2009.

[10] http://www.dssresearch.com/KnowledgeCenter/toolkitcalculators/statisticalpowercalculators.aspx.

[11] S. S. Verma and Y. K. Sharma, "Prediction of birth weight from simple anthropometric measurements in Indian male and female new born babies," Indian Journal of Medical Sciences, vol. 53, no. 2, pp. 68-76, 1999.

[12] WHO, "The incidence of low birth weight. A critical review of available information," World Health Statistics Quarterly, vol. 33, pp. 197-224, 1980.

[13] J. S. Weiner and J. A. Lourie, Practical Human Biology, Academic Press, New York, NY, USA, 1981.

[14] World Health Organization (WHO), "Diet, nutrition and the prevention of chronic diseases," Report of a Joint WHO/FAO Expert Consultation, World Health Organization, Geneva, Switzerland, 2003.

[15] W. P. T. James, G. C. N. Mascie-Taylor, N. G. Norgan, B. R. Bistrian, P. S. Shetty, and A. Ferro-Luzzi, "The value of arm circumference measurements in assessing chronic energy deficiency in Third World adults," European Journal of Clinical Nutrition, vol. 48, no. 12, pp. 883-894, 1994.

[16] K. Abu-Saad and D. Fraser, "Maternal nutrition and birth outcomes," Epidemiologic Reviews, vol. 32, no. 1, pp. 5-25, 2010.

[17] Y. Neggers, R. L. Goldenberg, S. P. Cliver, H. J. Hoffman, and G. R. Cutter, "The relationship between maternal and neonatal anthropometric measurements in term newborns," Obstetrics and Gynecology, vol. 85, no. 2, pp. 192-196, 1995.

[18] S. Kirchengast and B. Hartmann, "Impact of maternal age and maternal somatic characteristics on newborn size," American Journal of Human Biology, vol. 15, no. 2, pp. 220-228, 2003.

[19] http://www.unsystem.org/SCN/archives/scnnews11/ch06.htm. 


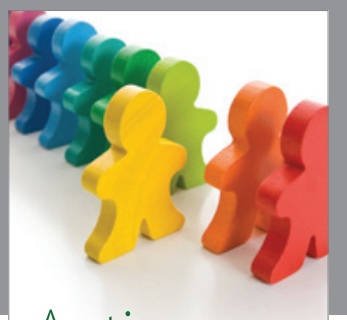

Autism

Research and Treatment
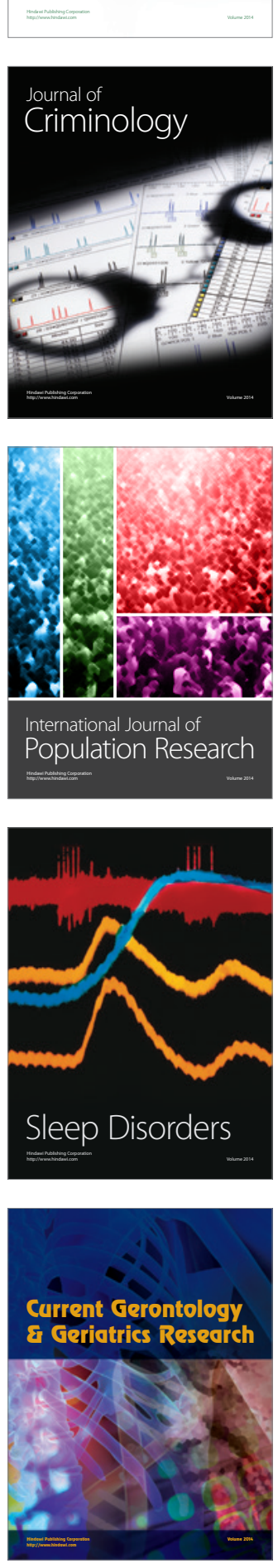
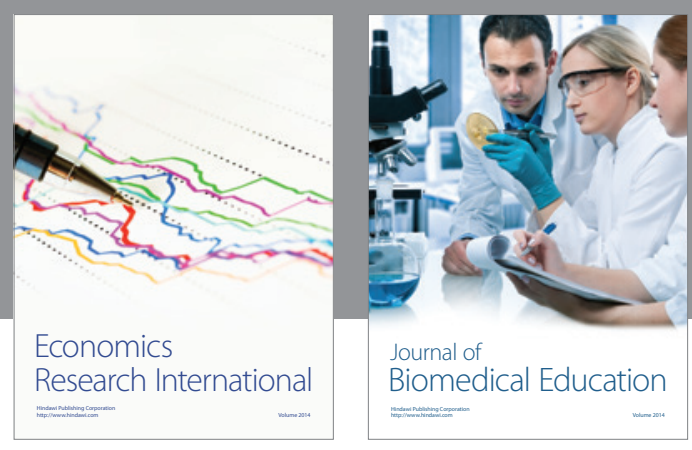

Journal of

Biomedical Education

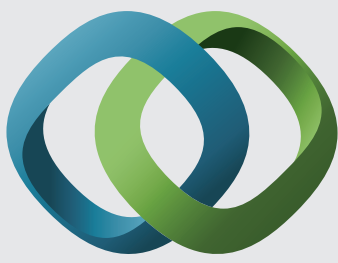

\section{Hindawi}

Submit your manuscripts at

http://www.hindawi.com
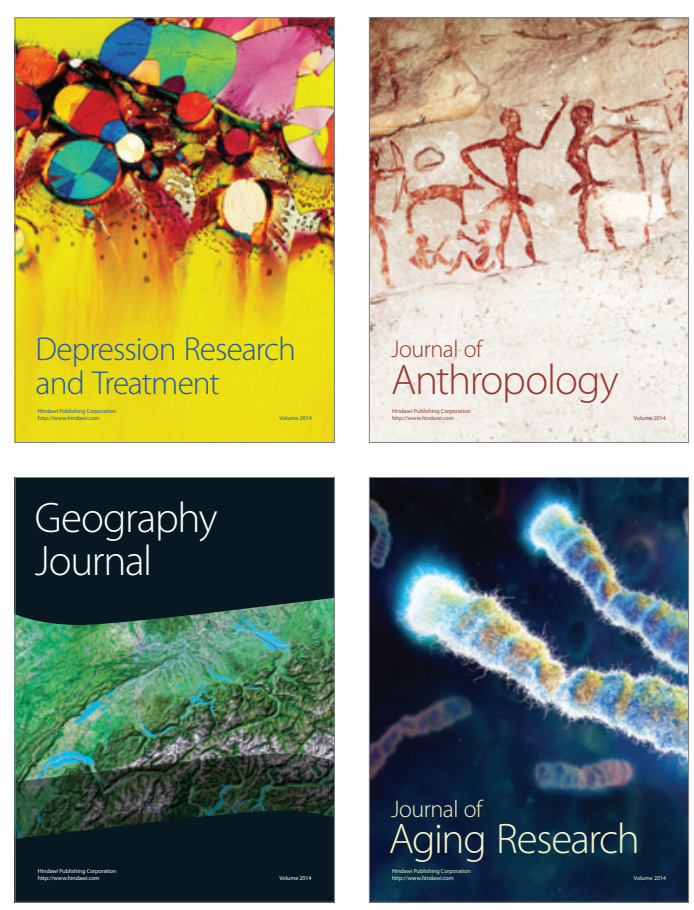

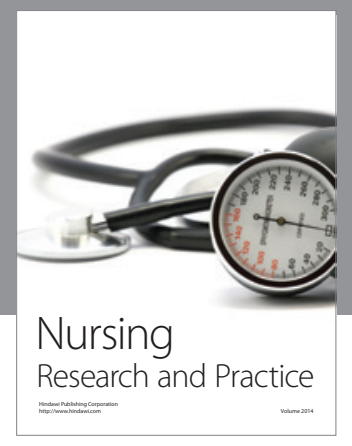

Nursing

Research and Practice

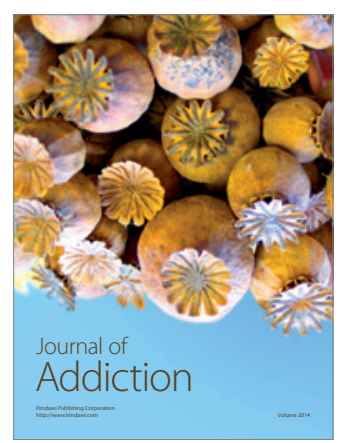

Child Development

Research

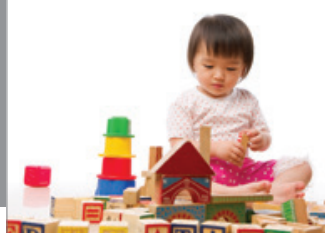

迥
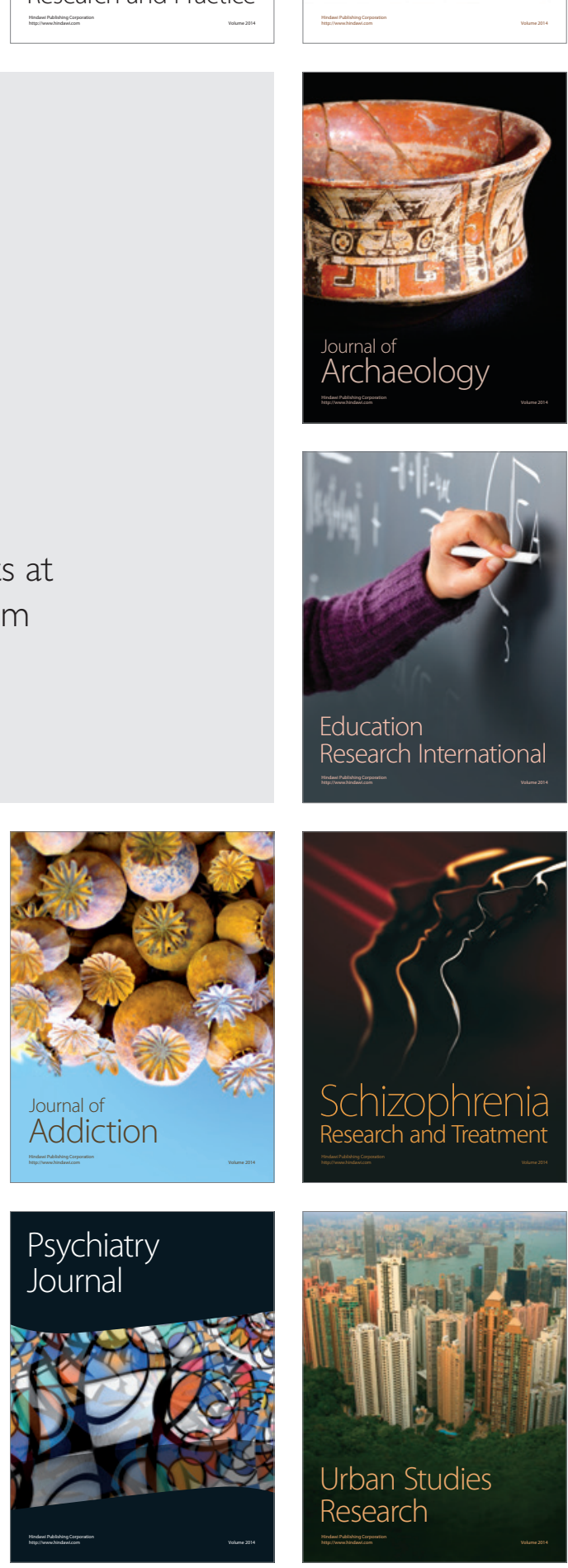